\title{
An evaluation of HDPE geomembrane exposed under extreme weather condition in Mongolia
}

\author{
Yongya Zheng ${ }^{\text {i) }}$ and Hoeboon $\mathrm{Ng}^{\text {ii) }}$ \\ i) Technical Manager, GSE Environmental Lining Technology (Suzhou) Co. Ltd., Shanghai Branch Company, Room 1807-1808, Floor \\ 18 Shanghai Trade Center, No.800 Quyang Road, Hongkou District, Shanghai 200437 China. \\ ii) Senior Technical Manager, GSE Lining Technology Co., Ltd., 555 Rasa Tower $26^{\text {th }}$ Floor, Phaholyothin Road Soi 19, Chatuchak, \\ Bangkok, 10900 Thailand.
}

\begin{abstract}
Geomembrane liner has been widely accepted as standard components of geosynthetic lining systems in many containment facilities. Among the plastic materials utilized for geomembranes, high density polyethylene (HDPE) geomembranes are the most widely used geosynthetic lining materials adopted for various containments applications include waste landfill, liquid containment and mining pond, etc. This is mainly attributed to its superior hydraulic and mechanical properties in combination with its very low permeable characteristics, greater chemical resistance and ultra violet light (UV) degradation resistance.

It is always engineers' major concern regarding the lifetime of geomembranes. The paper presents an evaluation of HDPE geomembrane liner that was left exposed to the extreme continental climate with long, cold winters and short summers in Northern Mongolia. After more than 16 years of service and exposure, geomembrane samples were evaluated for physical property integrity and engineering performance. The laboratory test results presented in this paper demonstrate that after 16 years in active service, HDPE geomembrane liners are working in their desired function and performance under exposed condition.
\end{abstract}

Keywords: HDPE geomembrane, extreme weather, lifetime, durability

\section{INTRODUCTION}

The paper presents a copper dump leach pad project located at the mining city, namely Erdenet, 241 kilometers northwest of Ulaanbaatar, Mongolia. Figure 1 shows the location of the mine site owned by "Erdmin Co., Ltd",. The city was built in 1974 to exploit Asia's largest deposit of copper ore and the fourth largest copper mine in the world. Erdenet Mining Corporation (EMC) is a joint venture between the governments of Mongolia and Russia, and was established in 1976. As of 2007, Edernet was accounted for over 14\% of Mongolia's gross domestic product (GDP).

First in 1994, at the initiative of ex-General Director Sh. Otgonbileg of EMC, "Erdenet Concern" LLC of Mongolia and "RMC" of the USA signed an agreement to build a pilot plant to manufacture pure copper cathode by using weakened solution of sulfuric acid (concentration 15-16\%) from low-grade ore piles of EMC. Thus, in February of 1997, "Erdmin Co., Ltd" was officially registered and opened to start producing copper by dump leach process. The raw ore grade average grade of copper ores is $0.6 \%$ at Erdmin, and the extraction rate after leaching is $51 \%$. Total copper annual output is 2,800 ton.

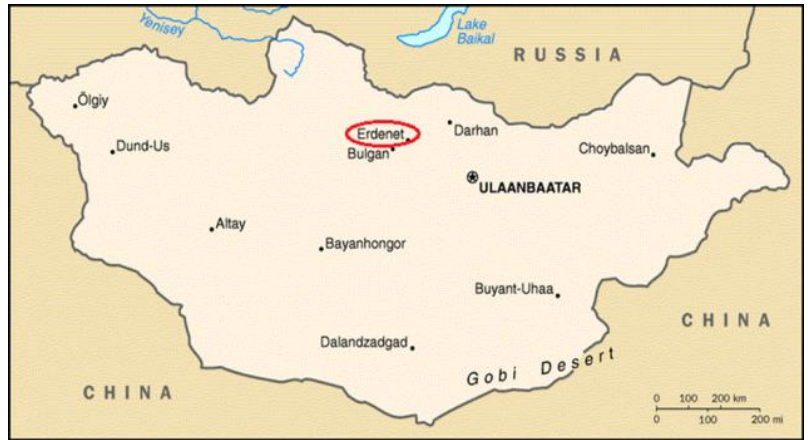

Fig. 1. The site location.

There are several copper beneficiation techniques according to ore types (sulfide ores or oxidized ores and ore grade). For sulfide ores, conventional milling/flotation is commonly used method. Leach operation (hydrometallurgical methods) are generally adopted for oxidized ores beneficiation. The crushed and grinded run-of-mine is stacked in the leach pad which is commonly lined with an impervious layer. Leach solution (usually weak sulfuric acid stored in the irrigation pond) is then sprayed over the top of the ore pile and allowed to percolate downward through the 
heap. Copper is converted into water soluble form through the reactions with chemical solutions. The pregnant leach solution (PLS) is then collected in pregnant solution pond and further conveyed to the nearby facilities through pipes or lined ditches to get the final product copper cathodes by solvent extraction or electrowinning method (SX/EW). The pregnant solution after extraction process (usually called raffinate and is stored in raffinate pond) is renewed, and the process is repeated until it is no longer economical.

The leach operations are relatively easy to design, lower capital and operational cost required, as well as shorter start up time. Based on the site selected for heap leach pad construction and maximum stack lift required for leaching process, the heap leach pad can be classified into four major categories, namely conventional pad, dump leach pad, valley-fill pad and dynamic on-off pad. Compared with the other three types of heap leach pad, dump leach pad lifts are thicker, able to accommodate extended leach times and operate in large range of climates. It is usually adopted for low grade ore leaching process. Figure 2 shows for the schematic diagram of dump leach pad process. Today waterproofing geomembrane and geosynthetic materials are commonly used in the copper leaching process for both environment protection and better recovery of leach solutions. Low permeable polymeric geomembrane has been widely used as the primary base liner for heap leach pad and process solution containments, such as pregnant solution pond, irrigation solution pond, raffinate solution pond, emergency pond, and even solution conveying ditches and channels.

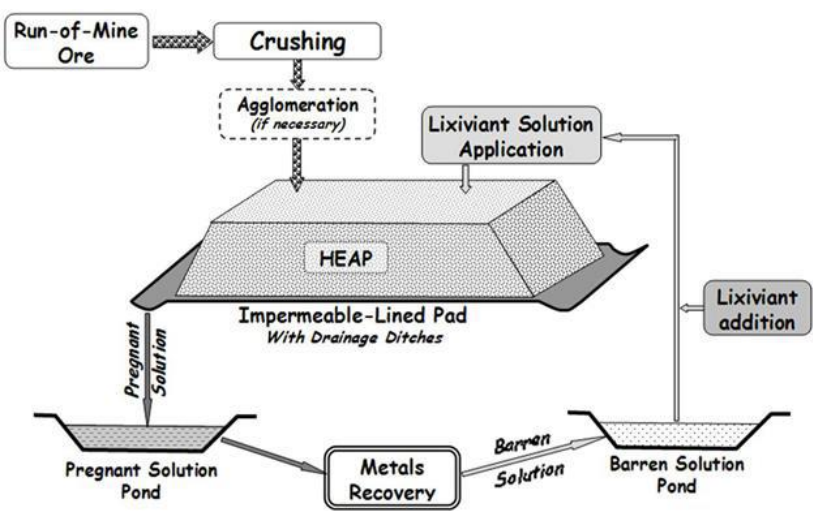

Fig. 2. Schematic diagram of dump leach pad process (Zanbak, C. 2012)

\section{PROJECT BACKGROUND}

In February 1997, “BKS” Consulting Engineers of USA and the Design Department of EMC carried out an analysis of the plant and have decided to use $2 \mathrm{~mm}$ thick smooth high density polyethylene (HDPE) geomembrane as the bottom liner system of the dump leach pad and eight attached solution ponds (see Figure 3 to 5). It is a single liner system with a geotextile cushion layer being placed under the geomembrane to serve as protection from sharp rocks or protruding objects that could be found in the compacted tailings subgrade. HDPE geomembrane was installed by a joint venture company between Russian and the local construction firm. The installation was completed within 4 months during spring and summer time. The total lining area is 100,000 square meters.

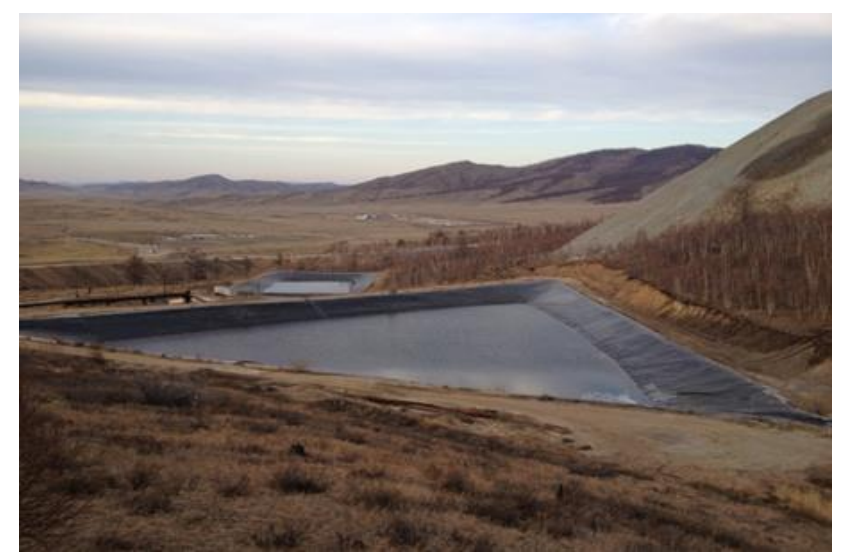

Fig. 3. One of the pregnant leach solution (PLS) ponds.

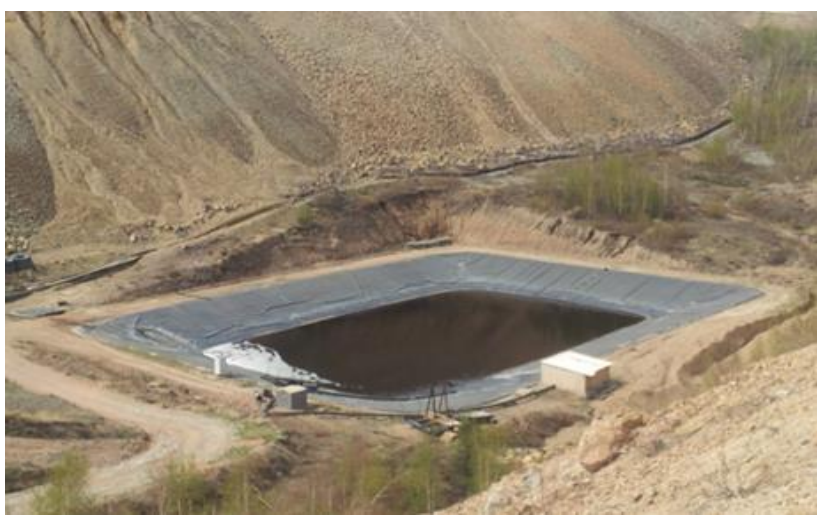

Fig. 4. One of the solution ponds.

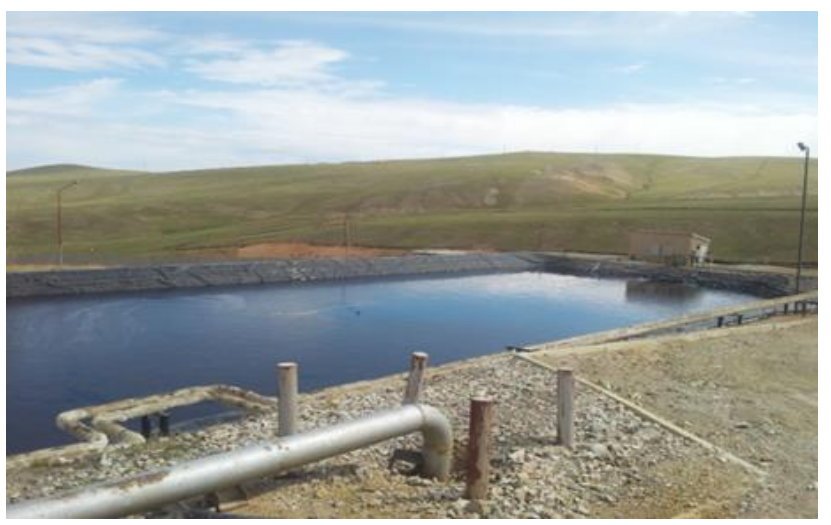

Fig. 5. One of the raffinate ponds.

Geosynthetics liner system applied in mining containments was the first time used in Mongolia at that time. The dump leach pad is $56 \mathrm{~m}$ high and four pregnant solution ponds were set up around the dump leach pad, connecting with geomembrane lined ditches, 
with total lining area of $12,800 \mathrm{~m}^{2}, 6,200 \mathrm{~m}^{2}, 5,000 \mathrm{~m}^{2}$, $5,000 \mathrm{~m}^{2}$, respectively. The total lining area of the two raffinate ponds was $2,700 \mathrm{~m}^{2}$ and about $1,200 \mathrm{~m}^{2}$ for the irrigation solution pond and waste impoundment pond respectively. The typical side slope gradient for the ponds was $2 \mathrm{H}: 1 \mathrm{~V}$ and the ponds have average depths of 4-6 meters. The level of water/liquid in the ponds varied according to the seasons and production schedule, which means the large portion of the geomembrane will be exposed to ultraviolet (UV) radiation over a period of time, especially when the water/liquid levels drop. But geomembrane at the upper portion of the slope, approximately 0.5 meters from the slope crest, was exposed to UV radiation all the time.

\section{THE WEATHER}

Mongolia is located in east-central Asia between China and Russia. The country's high altitude results in cold, dry and harsh weather. It has an extreme continental climate with long, cold winters and short summers, during which most precipitation falls. Average temperatures over most of the country are below freezing from November through March and are about freezing in April and October. January and February temperature averages of $-20^{\circ} \mathrm{C}$ are common, with winter nights of $-40{ }^{\circ} \mathrm{C}$ occurring most years. Summer extremes reach as high as $38{ }^{\circ} \mathrm{C}$ in the southern Gobi region and $33{ }^{\circ} \mathrm{C}$ in Ulaanbaatar. Summer lasts from June to August, with an average temperature of $20{ }^{\circ} \mathrm{C}$. Mongolia's weather is characterized by extreme variability and short-term unpredictability in the summer, and the multiyear averages conceal wide variations in precipitation, dates of frosts, and occurrences of blizzards and spring dust storms.

Erdenet is located in the northern part of the country, lies in a valley between the Selenge and Orkhon rivers about 241 kilometres northwest of the capital of Mongolia, Ulaanbaatar. The mining city is situated at an elevation of about $1,300 \mathrm{~m}$ above sea level, and receives stronger sunlight radiation annually than the plain area (annual solar energy 140kLy). From the historical weather record, the average highest and lowest temperature throughout a year is $21^{\circ} \mathrm{C}$ and $-26^{\circ} \mathrm{C}$, respectively. Based on the extreme temperature record, year 2013 as an example, it reached as high as $32^{\circ} \mathrm{C}$ in June, and dropped to $-37^{\circ} \mathrm{C}$ in February, in other words, the temperature differs over a year in Erdenet can be $70^{\circ} \mathrm{C}$. HDPE geomembrane applied under the inclement weather conditions over a long period of time can be a great challenge to its overall performance. The oxidation degradation of geomembrane in field conditions is affected by temperature, oxygen partial pressure, and chemical constituents of the surround media, e.g., $\mathrm{pH}$, transition metal ions, etc.

Lifetime predictions of hundreds of years have been estimated by several researches, i.e., Sangam and Rowe (2002), Rowe and Rimal (2008), Koerner (2012), illustrate the oxidation degradation of HDPE geomembranes. Geomembranes that are used in the exposed environment will have a significantly decreased life time compared to that under covered environment. Although the predicted lifetime of exposed geomembranes are considerably shorter than when the similar geomembranes are under covered condition, they are reasonable and are much higher than 20 years warranty which is common within the geomembrane industry (Koerner et al. 2012). Through laboratory UV weathering tests conducted by GSI, Koerner et al. (2012) reported that HDPE is very robust in its behavior at approximately 50-years for its half-life. This is almost ten-times lesser than the predicted lifetime for covered HDPE geomembranes. With the presence of UV radiation, the degradation mechanisms include UV radiation degradation from photo-oxidative and thermal degradation from thermo-oxidative ageing processes take place concurrently, expedite the antioxidants depletion hence a shorter lifespan.

UV radiation can be expected to cause deterioration in appearance as well as mechanical properties with time. However, a review of available literature investigating the UV resistance of HDPE geomembrane from field performance and laboratory test data provides evidence that exposure of a HDPE geomembrane to UV radiation for 20 years or more will not result in significant degradation of the geomembrane. The studies on the long term exposed geomembranes are generally performed in the US and the West. N. Ivy (2002) performed testing on $2.5 \mathrm{~mm}$ HDPE in both exposed and unexposed conditions after 20 years of service as containment ponds for a steam electric generating station in Colorado, USA. It is reported that no significant reduction in the primary physical properties was observed, except some reduction in OIT value caused by depletion of antioxidants, and with retained value more than half the initial value. Similar conclusions were made by C. Tarnowski and S. Baldauf (2006) after testing and study on exposed HDPE geomembrane samples from four different containment facilities respectively in Europe and West Asia after 30 years of service. These studies demonstrate that after 20-30 years, an HDPE liner, depending on the conditions to which it is exposed, can still perform its intended function.

Experience has also shown that exposed HDPE materials, including geomembranes, can perform satisfactorily for decades if they are protected from mechanical aggressions. There has been lack of record on the field performance of HDPE geomembrane liners in this region. The authors have therefore taken the initiative to establish a valuable data base of HDPE geomembrane in-service performance in the mining 
city. Laboratory evaluation on long term behavior and lifetime prediction of exposed HDPE geomembranes under such an extreme weather condition is the primary objective of this study. In this paper, laboratory test results on field exposed HDPE geomembrane samples collected from the jobsite are presented in the following section. The laboratory tests was performed to evaluate the effect of 16 years exposure to the natural weathering at the field and to estimate the remaining lifetime of the exposed HDPE geomembranes that have been installed after 16 years in active service.

\section{LABORATORY TESTING}

In the middle of 2013, exposed samples were collected from the field. A series of laboratory tests was carried out to study the effect of the exposed HDPE geomembrane after 16 years of service under local inclement weather condition. It is also the owner's interest to know the performance and approximate remaining lifetime of the exposed HDPE geomembranes in service.

All the ponds were still in operation during the sampling. Therefore, only samples on the upper side slope of pregnant solution ponds (PLS) were allowed to remove for the laboratory evaluation. Geomembranes at this location are above the liquid level and have permanently exposed to intensive UV radiation, high speed wind and natural weathering since installation.

HDPE geomembrane liners used in this project were produced in 1997. It was manufactured in compliance with the minimum requirement of GRI-GM13 specification. Coincidentally, the first edition of internationally recognized HDPE geomembrane specification, GRI-GM13 was published and adopted in the same year. Although several revisions were made to the specification during the past decade, the main content remains unchanged. As the QA/QC certificates for this material have been lost throughout the years, the initial test values obtained during manufacturing are not included in this evaluation. It was our intent to evaluate the sample properties as per GRI-GM13 specification. The following laboratory tests were performed on the field exposed samples:

- Density --- ASTM D1505;

- Tensile properties --- ASTM D6693 Type IV, 2 ipm;

- Tear resistance --- ASTM D1004;

- Carbon black content --- ASTM D4218;

- Notched tensile constant load (NCTL) --- ASTM D5397 Appendix

- Standard Oxidative induction time (OIT) --- ASTM D3895.

- High pressure OIT --- ASTM D5885;

Table 1 shows the minimum requirement of GRI-GM13 specification comparing with the laboratory test results of the field exposed samples collected from the jobsite. After 16 years of exposure under extreme climate, there is no apparent change in density. The densities of the field exposed samples are in the range of $0.950 \mathrm{~g} / \mathrm{cc}$. It remains almost the same with what would be expected for HDPE geomembranes and still within range of the typical values at the time this material was produced and installed.

All the mechanical test properties meet the minimum values of GRI-GM13 specification. This is expected because the geomembrane was not subjected to any chemicals that could be absorbed, affecting tensile properties, tear and puncture resistances. As expected the carbon black contents are reported within the acceptable testing variability, as the carbon black should not be leached out from the polymer in this environment. In addition, all samples show reasonably good carbon black dispersion results. During preparation of the paper, SP-NCTL is still in progress although it has exceeded the initial project specification of 200 hours (GRI-GM13 spec, First Version, 1997).

Table 1. Laboratory test results of the field exposed samples vs. the minimum requirement of GRI-GM13 Specification

\begin{tabular}{|c|c|c|c|}
\hline Test property & Test method & $\begin{array}{l}\text { GRI GM13 } \\
(2.0 \mathrm{~mm}) \\
\text { min. value }\end{array}$ & $\begin{array}{l}\text { Field } \\
\text { exposed } \\
\text { sample } \\
\end{array}$ \\
\hline Density & ASTM D1505 & 0.94 & 0.95 \\
\hline Tensile Properties & ASTM D6693 & & \\
\hline Break Strength, N/mm & Type IV , & 53 & 59 \\
\hline Yield Strength, N/mm & $2 \mathrm{ipm}$ & 29 & 43 \\
\hline Break Elongation, $\%$ & G.L. $=51 \mathrm{~mm}$ & 700 & 813 \\
\hline Yield Elongation, \% & G.L. $=33 \mathrm{~mm}$ & 12 & 17 \\
\hline Tear Resistance, $\mathrm{N}$ & ASTM D1004 & 249 & 306 \\
\hline $\begin{array}{l}\text { Puncture Resistance, } \\
\mathrm{N}\end{array}$ & ASTM D4833 & 640 & 800 \\
\hline $\begin{array}{l}\text { Carbon Black Content, } \\
\% \text { (range) }\end{array}$ & ASTM D4218 & $2-3$ & 2.5 \\
\hline $\begin{array}{l}\text { Standard OIT } \\
\text { Or }\end{array}$ & $\begin{array}{l}\text { ASTM D3895 } \\
\left(200^{\circ} \mathrm{C}\right)\end{array}$ & 100 & 84 \\
\hline High Pressure OIT & $\begin{array}{l}\text { ASTM D5885 } \\
\left(150^{\circ} \mathrm{C}\right)\end{array}$ & 400 & 279 \\
\hline
\end{tabular}

OIT is an indirect measurement of the amount of antioxidants in the geomembrane. Both Standard OIT and High Pressure OIT were conducted on the field samples. As it was unable to trace the initial test value of this material, the minimum requirement of the GRI-GM13 specification is used as the reference. The materials have virtually undergone degradation when compared between the retained OIT values of exposed sample with the minimum requirement of GRI-GM13. Reduction of OIT values below the minimum requirement of GM13 has indicated the depletion of antioxidants occurs over the past 16 years. Based on the typical test values during the manufacture of geomembrane obtained from the same production formulation, the initial standard OIT values is in the 
range of 130-170 minutes. By taking the average initial OIT value of 150 minutes, and following a first-order decay relationship (Koerner 2012) as shown Equation (1), stage A antioxidants (AO) depletion rate of the exposed samples can be estimated.

$$
\ln (\mathrm{OIT})=\ln (\mathrm{P})-(\mathrm{S})(\mathrm{t})
$$

where $\mathrm{P}=$ initial value of OIT in the geomembrane (minutes), $\mathrm{S}=\mathrm{AO}$ depletion rate $\left(\right.$ month $\left.^{-1}\right), \mathrm{t}=$ ageing time (months or years), OIT $=$ OIT at time $t$ (minutes)

Based on the typical OIT values obtained during the manufacture of HDPE geomembranes of same formulation, it can be estimated that the depletion of antioxidants (stage A) present in the geomembranes progressed at approximately 0.00302 month $^{-1}$. Through the above equation and the interpreted $\mathrm{AO}$ depletion rate, the exposed HDPE geomembrane should be able to continue perform for several decades. It is our plan to revisit the site for sampling and carrying out laboratory evaluation on the exposed HDPE geomembrane with time as to establish a data base on the ageing resistance of HDPE geomembranes in the region.

\section{SUMMARY AND RECOMMENDATIONS}

HDPE geomembranes have been installed and exposed to the extreme weather condition with annual solar energy $140 \mathrm{kLy}$ in the mining city, Edernet, Mongolia. Until today all the lined ponds and containments are still performing as desired. Samples were taken from the side slope of a PLS pond which was permanently exposed to the UV radiation for 16 years. The paper presents results of laboratory tests performed on field exposed samples to evaluate the physical properties and mechanical integrity of HDPE geomembrane in-service. In addition, the paper presented the antioxidants depletion of the exposed HDPE geomembranes after 16 years in active service.

The laboratory evaluation on the field exposed samples has revealed that no significant reduction in the physical and mechanical properties was observed. All the test properties generally meet the minimum specification of GRI-GM13 standard. Changes in OIT values clearly revealed that the ageing process is undergoing. The retained OIT values also verified the ability of the geomembrane to continue working as impermeable barrier exposed to the extreme environment for decades.

Today all the lined ponds are still functioning as desired. "We are very satisfied with the performance of the geomembrane applied in our dump leach pad, it helps us to maintain a normal and effective operation in the facility", an acknowledgement by Mr. J. Baatar, General Director of Erdmin Co., Ltd. In addition, the quality of cathode copper manufactured by Erdmin through dump leach processing has been confirmed by "Alex Steward Assayers", a well-known British company, and meets "A" grade quality requirements of
London Metal Exchange. Erdmin also set up 18 wells to monitor the underground water quality twice a month. The monitoring results throughout year 2013 indicated that the average $\mathrm{PH}$ values of the water sample ranged from 5.85 to 7.66, and concentration of $\mathrm{Cu}$ cation kept in a very low level.

In conclusion, the high quality HDPE geomembrane product used in the dump leach pad, as an impermeable water barrier, has withstood the test of time under inclement weather condition and is expected to continue perform as desired for few more decades.

The laboratory test results presented in this paper demonstrate that after 16 years in active service, the well-stabilized HDPE geomembranes are still serving the intended purpose under extreme weather condition. The authors found that the well-stabilized HDPE geomembranes are also performing satisfactorily at other region in Asia-Pacific ( $\mathrm{Ng}$ and Chayapornlert, 2014). A higher quality geomembrane manufactured today is expected to perform better and live longer, primarily due to technological improvements in resin stabilization and sheet manufacturing techniques. The results presented in this paper demonstrate that it is inadequate by only referring to the initial OIT value which is just an index figure to show sufficient amount of antioxidants in the geomembrane immediately after manufacture. The retained OIT after laboratory accelerated ageing should also be specified in every material specification in order to obtain a meaningful data on the durability of geomembranes. Most importantly, use of appropriate geomembrane grade resin formulation for the specific applications will allow a better protection against thermal and UV degradation, thus ensure a longer performance of containment systems.

\section{ACKNOWLEDGEMENTS}

The authors wish to express sincere appreciation to Erdmin Co. Ltd., and Mr. Ganbold B. for their valuable contribution to this paper.

\section{REFERENCES}

1) Zanbak, C. (2012): HAEP LEACHING TECHNIQUE in MINING. The European Association of Mining Industries, Metal Ores \& Industrial Minerals. p.13.

2) Sangam, H.P., and Rowe, R.K. (2002): Effects of Exposure Conditions on the Depletion of Antioxidants from high-density polyethylene (HDPE) Geomembranes. Canadian Geotechnical Journal, 39, p. 1221-1230.

3) Rowe, R.K., and Rimal, S. (2008): Depletion of Antioxidants from an HDPE geomembrane in a Composite Liner. Journal of Geotechnical and Geoenvironmental Engineering, ASCE, 134(1), p. 68-78.

4) Koerner, R. M. (2012): Designing with Geosynthetics. 6th Edition, Xlibris Corporation, USA, p. 555-564.

5) Koerner, R. M., Koerner, G. R., Hsuan, Y. G., Wong, W. K. C. (2012): Lifetime Prediction of Laboratory UV Exposed Geomembranes: Part I-Using a Correlation Factors. GRI Report \#42, Folsom, Pennsylvania, USA. 
6) Ivy, N. (2002): HDPE geomembrane after 20 years of service. GFR, June/July 2002.

7) Tarnowski, C. Baldauf, S. (2006): Aging resistance of HDPE-geomembrane - Evaluation of long-term behavior under consideration of project experiences, Geosynthetics, J. Kuwano \& J. Kosaki (eds), Millpress, Rotterdam, N.L.D., p.359-362.

8) Geosynthetic Research Institute. 2012: GM-13 "Standard Specification for Test Methods, Test Properties and Testing Frequency for High Density Polyethylene (HDPE) Smooth and Textured Geomembranes", Folsom, Pennsylvania, USA.

9) Ng, H.B. and Chayapornlert, S. (2014): Evaluation of Exposed HDPE Geomembranes under Tropical Climate. Proc. of $7^{\text {th }}$ ICEG, 11-14 Nov. 2014, Melbourne, Australia, p. 672-679. 